\title{
Factors Contributing to Haze Formation and the Influence on Power Equipments External Insulation
}

\author{
Zhicheng Zhou ${ }^{1}$, Song Gao ${ }^{1, ~ a, ~ L i n j u n ~ Y a n g ~}{ }^{2, b}$, Yong Liu ${ }^{2}$, \\ Fengbo Tao ${ }^{1}$, Long Zhang ${ }^{1}$ \\ ${ }^{1}$ Jiangsu Electric Power Company Research Institute, Nanjing, China \\ ${ }^{2}$ School of Energy and Environment, Southeast University, Nanjing, China \\ ahvgaosong@foxmail.com, bylj@seu.edu.cn
}

\begin{abstract}
Keywords: Haze, PM2.5, External insulation, Pollution flashover voltage, High conductivity fog Abstract. Haze-fog has been a severe pollution weather phenomenon in China due to a large number of emissions of pollutants with the rapid development of economy. The areas burst haze are usually coincidence with high density of electricity transmission line corridor or power load areas, and so the pollution flashover accidents happen frequently. In this paper the haze pollution situations and factors contributing to haze are introduced, and the mechanisms of haze inducing and aggravating the pollution flashover accidents are explained by analyzing the temporal and spatial distribution of PM2.5 and size characteristics of dust deposited transmission. Moreover, the influences of haze on power transmission and transformation equipment external insulation are discussed with combining the simulation pollution flashover experiments of high conductivity fog.
\end{abstract}

\section{Introduction}

China has become one of the most serious polluted areas by PM2.5. Beijing-Tianjin-Hebei and Yangtze River Delta districts are the hardest-hit areas. At present, the haze weather caused by PM2.5 pollution has been the most serious problem in atmospheric environment and people's livelihood[1]. Atmospheric pollution evolved from a coal-burning pollution to cross regional and complex air pollution. In January 2013, central and eastern regions of China went through the most serious haze weather in recent ten years. Four of these haze phenomena spread to 30 provinces. According to the data of the ministry of environmental protection, the air qualities of 104 cities in 20 provinces were heavy pollution[1-2].

The areas burst haze are usually coincidence with high density of electricity transmission line corridor or power load areas. At present, the influence of haze weather on human health and atmospheric visibility has already caused extensive concern, but the impact of haze on power transmission and transformation equipment has not received enough attention. Transmission line insulator would be happen pollution flashover in the operation process as affected by industrial emissions or natural dust and other environmental factors, and haze could induce and intensify this process. There is a close relationship between aggravating of flashover pollution and haze pollution characteristics. Pollution flashover is one of the disastrous accidents threaten the security of the electric power system. In the past 20 years, the pollution flashover caused by haze broke out frequently and obviously increased with the haze more and more serious. In February 2001, the most serious pollution flashover accident happened in Liaoning province of China since the founding of the Liaoning electric power grid, and $500 \mathrm{kV}$ line tripping[3-4]. With the increase of the grid voltage and capacity, the loss caused by pollution flashover will be greater. Therefore, it is necessary to make deep analysis of the characteristics, formation causes of fog-haze and its influence on the insulation of power transmission and transformation equipment, in order to avoid the deterioration of pollution flashover. 


\section{Pollution characteristics of haze weather}

There is a close relationship between pollution characteristics of haze weather and PM2.5 time-space distribution, which is depended on the meteorological conditions (such as wind speed, air temperature, atmospheric stability, etc) and distribution of pollution sources.

Temporal distribution characteristics of $\mathbf{P M}_{2.5}$. Diurnal variation: In general, there are two peaks (morning and evening) of $\mathrm{PM}_{2.5}$ concentration a day. This phenomenon is related to the meteorological environment and human activity. A negative correlation between $\mathrm{PM}_{2.5}$ concentration and air temperature variation is existed. That is, $\mathrm{PM}_{2.5}$ concentration decreases with an increase of air temperature and vice versa. In addition, pollution of exhaust from cars is more serious during the rush hours. Seasonal variation: The highest concentration of $\mathrm{PM}_{2.5}$ usually appears in December and January. This is because that the adverse meteorological conditions for $\mathrm{PM}_{2.5}$ diffusion are easy to appear at this time. Therefore, serious haze weather usually occurred in December and January.

Spatial distribution characteristics of $\mathbf{P M}_{2.5}$. Due to the preferable following performance to airflow of $\mathrm{PM}_{2.5}$, there is better time-space relativity of the $\mathrm{PM}_{2.5}$ concentration at different heights. Pollutions discharged from various emission sources would mix and superpose in a certain area with air diffusion. $\mathrm{PM}_{2.5}$ is mainly distributed in the atmospheric mixed layer. $\mathrm{PM}_{2.5}$ concentration is almost homogeneous in the mixed layer. Hence, there is almost no difference of $\mathrm{PM}_{2.5}$ concentration at different heights except construction sites, main trunk of the traffic. The monitoring data indicate that $\mathrm{PM}_{2.5}$ concentration is almost homogeneous in the heights of 300 500 meters. Moreover, the characteristic of $\mathrm{PM}_{2.5}$ vertical distribution is also related to the meteorological condition. The difference of $\mathrm{PM}_{2.5}$ concentration is relatively lesser in the better atmospheric diffusion conditions, which is beneficial to the diffusion and mixing of $\mathrm{PM}_{2.5}$ at different heights.

Regional characteristic of haze pollution. Regional characteristic of haze pollution is closely related to the regional characteristic of $\mathrm{PM}_{2.5}$ pollution. There is a certain difference of the $\mathrm{PM}_{2.5}$ concentration at different local area. However, an obvious regional distribution characteristics of $\mathrm{PM}_{2.5}$ concentration appears in the entire region. This is because that $\mathrm{PM}_{2.5}$ can follow the airflow well. The two serious haze process in January and December 2013 shows distinct regional characteristic (see Fig.2 ).

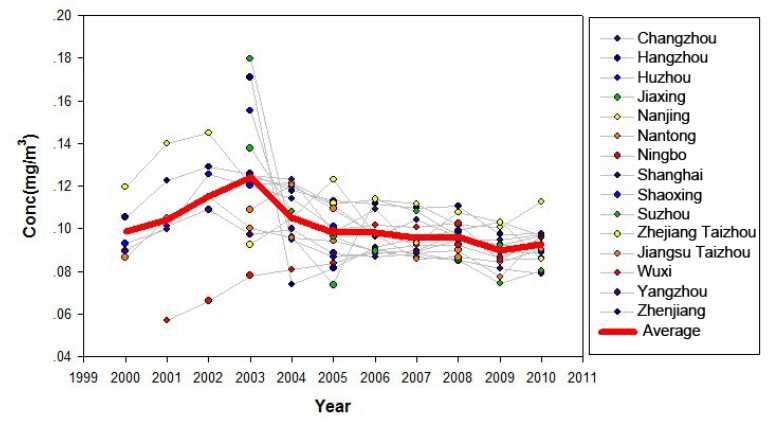

Fig.1 Regional characteristic of PM2.5 pollution Yangtze river delta region as example)

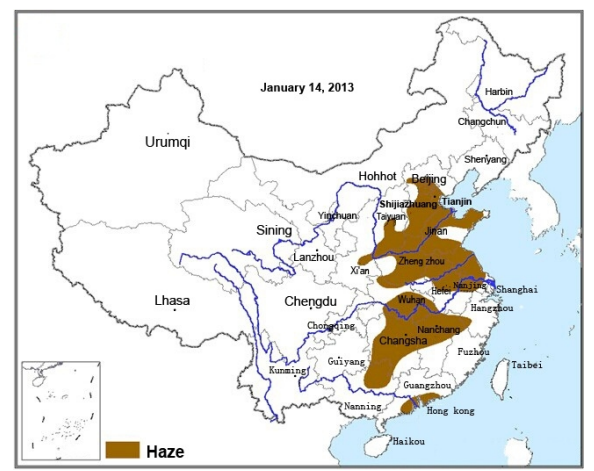

Fig.2 Regional characteristic of haze (Take pollution

\section{Analysis of haze formation}

Climatic factor.Haze is the result of the natural factors and human activities. Due to the adverse atmospheric diffusion conditions, pollutions accumulate in the low altitude when the haze weather occurs. Meanwhile, secondary pollutions would generate by the interaction of fog drop and fine particles. A wide range of haze weather most appears at the condition of large-scale atmospheric circulation with weaker cold air and better water vapor condition. In this case, wind condition in the low altitude is breeze or calm wind. Air mobility in the horizontal and vertical is poor, which would cause an adverse atmospheric diffusion condition. On the one hand, the calm wind in the horizontal direction is not beneficial for the dispersion and dilution of airborne particulates. Then these particulates accumulate in the urban and suburban areas. On the other hand, due to the temperature inversion in the vertical direction, the hot and light air rise up to the cold and heavy air, which would 
cause the formation of an extremely stable air layer? The airborne particulates in the low altitude are difficult to drift away to high altitude and remain in the ground layer. In addition, the moisture content of air is relatively higher for the haze weather. These fog drops provide adsorption and reaction sites for gaseous pollutants, which can accelerate the gaseous pollutants to transform to liquid particles. Particles can also act as nucleation center to form haze.

Pollutants emission. Enhancement of $\mathrm{PM}_{2.5}$ concentration caused by the pollutants emission is the main reason of haze weather. At present, the consumption of coal, production of steel and cement, car ownership all rank the first in the world. The total discharge amount of sulfur dioxide and oxynitride has exceeded 22 million tons, which is the largest in the world. The discharge of industrial dust has increased to 14.461 million tons. This is far beyond the environmental supporting capacity. The primary pollution sources of $\mathrm{PM}_{2.5}$ include industrial emission, motor vehicle exhaust and construction fugitive dust. In which, industrial emission is the most important source. According to annual report of 2012, the discharge amounts of $\mathrm{SO}_{2}, \mathrm{NOx}$ and dust are 21.176, 23.378 and 12.343 million tons, respectively. Among these, $90.3 \%$ of $\mathrm{SO}_{2}, 70.9 \%$ of $\mathrm{NOx}$ and $83.4 \%$ of dust are discharged from thermal power, steel manufacture and architectural material industry. Moreover, the volatile organic compounds (VOCS) are exhausted from discharged from industry as well. In a word, thermal power, steel manufacture, cement, metallurgy, petrifaction and chemical engineering are the six key industries leading to the rise of $\mathrm{PM}_{2.5}$ concentration. The analysis shows that haze weather usually appears in the areas that are concentrated by electric power, steel, cement, petrifaction industries. Haze weather takes place frequently in Beijing-Tianjin-Hebei, Yangtze River Delta and Pearl River Delta districts is closely related to the high pollutants concentration. Motor vehicle exhaust is another important pollution source of $\mathrm{PM}_{2.5}$. It is estimated that the car ownership in China has exceed one hundred million. Atmospheric pollution in big or middle city begins to appear in a complex air pollution of coal-burning pollution and motor vehicle exhaust. Furthermore, some inorganization emissions (such as construction fugitive dust, lampblack and straw combustion, etc.) also make a significant contribution to the rise of $\mathrm{PM}_{2.5}$ concentration.

\section{The relationship of atmospheric particles and power equipment contaminate sediment}

$\mathbf{P M}_{2.5}$ composition and morphology characteristics in the atmospheric environment. $\mathrm{PM}_{2.5}$ in the atmospheric environment includes primary particulate and secondary particulate. The primary particulates are discharged directly to atmospheric environment, and the secondary particulates are the reaction products of gaseous pollutants (such as $\mathrm{SO}_{2} 、 \mathrm{NOx} 、 \mathrm{VOCs}$, etc.) with particulate matter[2]. As shown in Fig.3, the compositions of $\mathrm{PM}_{2.5}$ usually include organic matter, black carbon, sulfate, nitrate, ammonium salt and crustal elements. In which, most of black carbon and crustal elements are derived from the primary pollutants. Organic matters are both released from the primary pollutants and secondary pollutants. A majority of sulfate, nitrate and ammonium salt are the photochemical reaction products of $\mathrm{SO}_{2}$ and NOx. Fig.4 shows the morphology characteristics of $\mathrm{PM}_{2.5}$ in the atmospheric environment. It can be seen that $\mathrm{PM}_{2.5}$ in the atmospheric environment are not regular sphere, and appears different morphologies.

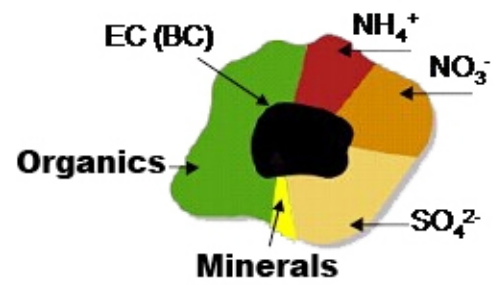

Fig.3 Chemical composition of $\mathrm{PM}_{2.5}$ in the atmospheric environment 


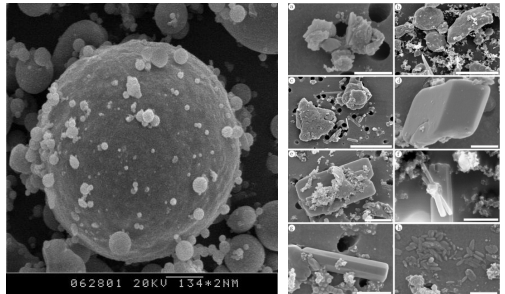

(a) Black carbon (b) Minerals
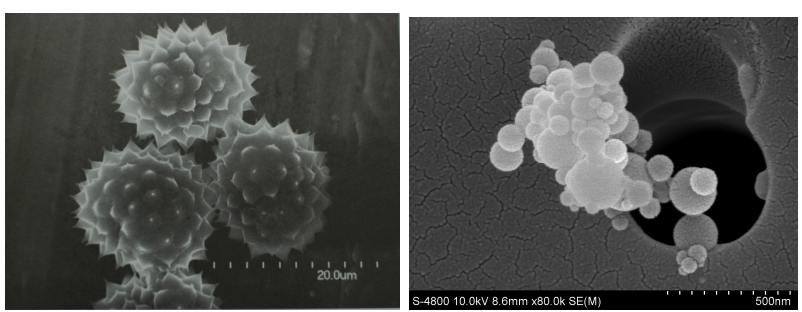

(c) Pollen

(d) Mixture of multiple particulates

Fig.4 Morphology characteristics of $\mathrm{PM}_{2.5}$ in the atmospheric environment contribution to the enhancement of $\mathrm{PM}_{2.5}$ concentration.

Pollution deposits particle size distribution of power equipment.The atmospheric particulates depositions on the surface of the power transmission and transformation equipment external insulation have a certain relationship with particle size. Characteristics and differences of deposits can be understudied and compared to each other through some characteristic particle size. Statistical analysis method can be used to get the characteristic particle size for particles deposited on the insulator surface and particles existed in the atmosphere with TSP or dust. Table 1 gives the samples particle size analysis results and the statistics characteristics size from two environmental monitoring point, Wuxi city, Jiangsu province of China. The results show that the surface insulator contaminants and dustfall particle sizes are relatively large, and the characteristics of particle size distributions are similar. However, the insulator contaminants spectral width is wider, and the mass mean diameter is bigger. The particle sizes of TSP are small, uniform distribution and spectrum width, and have minimum difference between characteristic diameters. It shows the sources of the contaminated deposits of grid equipment include dustfall and TSP, and the contribution rate of $\mathrm{PM}_{2.5}$ is very limited.

In addition, the survey also found that the average contaminated particle size under surface of insulator is smaller than the upper surface, which is consistent with the particles are more easily adsorbed under surface. The different diameter features of insulator surface contaminations are roughly the same, which is slightly different with pollution source of industrial dust, probably because of the dust particle of township industrial emissions deposited on the insulator surface.

The samples of insulator contaminants and dustfall, TSP are collected in the same height, and the difference of particle size distribution between them is only related to sampling method.

Table 1 The atmospheric particle size analysis and the contaminated surface particles of the insulator

\begin{tabular}{|c|c|c|c|c|c|c|c|c|c|c|c|c|}
\hline \multirow[b]{2}{*}{$\begin{array}{l}\text { Particulate } \\
\text { Types }\end{array}$} & \multirow[b]{2}{*}{$\begin{array}{l}\text { Monitor } \\
\text { Site }\end{array}$} & \multirow[b]{2}{*}{$\begin{array}{l}\text { Height } \\
(\mathrm{m})\end{array}$} & \multirow[b]{2}{*}{ Surface } & \multicolumn{6}{|c|}{ Particles Size Distribution (z) } & \multirow{2}{*}{$\begin{array}{c}\text { Mode } \\
\text { Diamet } \\
\text {-er } \\
(\mu \mathrm{m}) \\
\end{array}$} & \multirow{2}{*}{$\begin{array}{c}\text { Mean } \\
\text { Diamet } \\
-e r \\
(\mu \mathrm{m}) \\
\end{array}$} & \multirow{2}{*}{$\begin{array}{c}\text { Mean } \\
\text { Mass } \\
\text { diameter } \\
(\mu \mathrm{m}) \\
\end{array}$} \\
\hline & & & & $<2$ & $2 \sim 10$ & $\begin{array}{c}10 \sim \\
25\end{array}$ & $\begin{array}{c}25 \sim \\
50\end{array}$ & $\begin{array}{l}50 \sim \\
100\end{array}$ & $>100$ & & & \\
\hline \multirow{2}{*}{ TSP } & QianZhou & \multirow{2}{*}{30} & & 95.9 & 3.6 & 0.5 & - & - & - & 2.0 & 2.4 & 19.2 \\
\hline & DouShan & & & 69.3 & 29.8 & 0.9 & - & - & - & 2.0 & 4.6 & 14.8 \\
\hline \multirow{2}{*}{ dustfall } & QianZhou & 20 & & 11.4 & 80.5 & 7.6 & 0.5 & - & - & 10.0 & 10.4 & 25.9 \\
\hline & DouShan & 10 & & 7.0 & 66.7 & 14.4 & 11.3 & 0.6 & - & 10.0 & 16.6 & 57.1 \\
\hline \multirow[b]{2}{*}{ insulator } & \multirow[b]{2}{*}{ QianZhou } & \multirow[b]{2}{*}{20} & upper & 2.9 & 75.6 & 10.1 & 6.1 & 3.8 & 1.0 & 10.0 & 18.7 & 99.4 \\
\hline & & & lower & 5.3 & 78.5 & 14.2 & 2.3 & 0.6 & 0.6 & 10.0 & 14.2 & 99.5 \\
\hline
\end{tabular}

\section{Effects of haze on external insulation of power equipment}

The mechanism of haze inducing and aggravating the flashover. Environmental monitoring result shows that the pollutants concentrations near the ground are often sudden increase in haze weather, which is closely related with the surrounding industrial pollution sources. The maximum moisture content is in the top of fog at the beginning of the formation of fog. The moisture content gets maximum down to near ground when the fog thickened. Droplet condensed by fine particles nuclei such as ammonium sulfate in the atmosphere pass through the $\mathrm{SO}_{4}{ }^{2-}$ region in the settlement process, the liquid phase will happen with absorption/release, ionization and oxidation reaction in the droplet. The theoretical calculation and observation analysis show that the distribution of $\mathrm{SO}_{4}{ }^{2-}$ is related to the height of pollution source and the location of maximum moisture content, namely the more effective pollution source height, the higher $\mathrm{SO}_{4}{ }^{2-}$ concentration. In the vicinity of the same pollution source, the maximum moisture content enhances or the moisture content reduces, and the ground 
$\mathrm{SO}_{4}{ }^{2-}$ concentration get greater. The acidity distribution generally follows this rule in the fog. This is because the droplets will clear the $\mathrm{SO}_{2}$ in the upper plume and release $\mathrm{SO}_{2}$ in the lower plume during descending process. The release quantity at the ground will become the strongest near the pollution source and raises when the pollution source heightened. So not only the fog cannot clear $\mathrm{SO}_{2}$, but will increase the $\mathrm{SO}_{2}$ concentration in the atmosphere.

Besides $\mathrm{SO}_{4}{ }^{2+}$, haze also contains $\mathrm{NO}_{3}{ }^{-}, \mathrm{NH}_{4}{ }^{+}, \mathrm{Ca}^{2+}, \mathrm{Na}^{+}, \mathrm{Mg}^{2+}$, etc. with the increase of fog water conductivity, the contamination degree of the insulator surface increasing, and the pollution flashover voltage decreased. Research shows that the contamination degree of insulator surface will increase in a short period of time when occurring fog-haze, the surface equivalent salt density increased $0.01 \sim 0.04 \mathrm{mg} / \mathrm{cm}^{2}$ in dozens of hours, ash density increased $0.05 \sim 0.2 \mathrm{mg} / \mathrm{cm}^{2}$, surface contamination degree increased with fog-haze going on. The phenomenon is especially significant when $\mathrm{PM}_{2.5}$ is mainly composed of secondary particle, such as sulfate, nitrate and ammonium salt, or when coastal regional atmospheric are high in sea salt. Usually the haze is the most dangerous wet condition for contaminated insulator. Haze can make the surface contamilated layer of the insulator relatively slowly and evenly damp. The external insulation fall to the lowest level when the contaminated layer surface conductivity reaches the maximum with saturated moist condition[5-7].

Natural contaminated insulator flashover performance in the simulation haze-fog. For simulating the deposition process on the surface of the insulator and the influence on insulators in high conductivity haze, this paper designed a simulation test to supplement the shortage of field observation. The study was conducted on the same fog water salinity, which is simulated with $\mathrm{NaCl}$. The conductivities were $1800 \mathrm{~s} / \mathrm{cm}$ and $400 \mathrm{~s} / \mathrm{cm}$. Under the same fog water conductivity, pollution flashover test were conducted on the natural contaminated insulators and artificial contaminated insulator treated with IEC60507 solid layer method. The test samples were XP-160 type porcelain insulator, and the salt density of natural contaminated insulator was $0.2 \mathrm{mg} / \mathrm{cm}^{2}$, then the equivalent salt deposit density of artificial contaminated insulator, which using $\mathrm{NaCl}$ to simulate the soluble salt of insulator, is $0.1 \mathrm{mg} / \mathrm{cm}^{2}$.

Table 2 Influence of simulated fog and water fog on flashover voltage of contaminated insulator

\begin{tabular}{|c|c|c|c|c|c|}
\hline \multirow{2}{*}{$\begin{array}{c}\text { serial } \\
\text { number }\end{array}$} & \multirow{2}{*}{$\begin{array}{l}\text { Contaminated } \\
\text { layer type }\end{array}$} & \multirow{2}{*}{$\begin{array}{l}\text { equivalent } \\
\text { salt density } \\
\left(\mathrm{mg} / \mathrm{cm}^{2}\right)\end{array}$} & \multicolumn{2}{|c|}{ flashover voltage U $(\mathrm{kV})$} & \multirow{2}{*}{$\begin{array}{c}\text { deviation } \\
(\%)\end{array}$} \\
\hline & & & $\mathrm{U}_{400 \mu \mathrm{s} / \mathrm{cm}}$ & $\mathrm{U}_{1800 \mu \mathrm{s} / \mathrm{cm}}$ & \\
\hline 1 & natural & 0.2 & 70 & 53 & $24.2 \%$ \\
\hline 2 & natural & 0.2 & 69 & 54 & $21.7 \%$ \\
\hline 3 & artificial & 0.1 & 53 & 44 & $17.0 \%$ \\
\hline 4 & artificial & 0.1 & 47 & 40 & $14.9 \%$ \\
\hline 5 & artificial & 0.1 & 58 & 49 & $15.5 \%$ \\
\hline 6 & artificial & 0.1 & 43 & 38 & $11.6 \%$ \\
\hline
\end{tabular}

Table2 show that: (1) The haze conductivity influences the flashover voltage of natural contaminated insulators, and the pollution flashover voltage increase with the fog-haze conductivity decreased. (2) Effects of simulated contaminated haze on the flashover voltage of natural contaminated insulators are larger than on artificial solid layer insulators. The pollution flashover voltage of natural contaminated insulator in simulated fog-haze $(1800 \mu \mathrm{s} / \mathrm{cm})$ decrease with $21.7 \sim 24.2 \%$ than in water fog $(400 \mu \mathrm{s} / \mathrm{cm})$, but the flashover voltage of artificial simulation layer Insulator only decrease with $11.6 \sim 17.0 \%$. Generally the effects of natural contaminated insulator are larger than artificial simulation layer Insulator, because the surface contamination layer adhesion of natural contaminated insulator is fastening and the pollutants are not easy to be washed away. 


\section{Conclusions}

(1) The characteristics of regional pollution of fog-haze are closely related with $\mathrm{PM}_{2.5}$ pollution, and the adverse weather conditions and great pollution emission load are the main factors leading to fog-haze, industrial emissions is the main pollution source to increase the concentration of $\mathrm{PM}_{2.5}$ in ambient air.

(2) In view of the particle size distribution characteristics, the sources of contaminated deposits in power equipments contain dust fall and TSP, while the $\mathrm{PM}_{2.5}$ contribution rate is not significant, the simulation test results show that the influence of high conductivity in fog-haze weather on transmission line insulator is relatively large.

\section{References}

[1] J. Y. Cao: $P M_{2.5}$ and Environment, (Science Press, Beijing, 2014).

[2] X. Y. Chen, J. Y. Sun, Y. Q. Wang: Chin Sci Bull, Vol.58 (2013), p. 1178-1187

[3] Y. G. Li, C. C. Huang, F. C. Wang: Power System Technology, Vol. 38-7 (2014), p. 1792 1797

[4] X. L. Jiang, S. H. Zhao, M. Q. Bi: Proceedings of the CSEE, Vol. 33-31 (2013), p. 220 226

[5] D. F. Yu, C. X. Sun, L. G. Shun: Proceedings of the CSEE, Vol. 21-4 (2001), p. 15 19

[6] X. K. Hao: Energy and Energy Conservation, Vol. 106-7 (2014), p. 173 174

[7] Z. Y, Su: Power System Technology (In Chinese). Vol. 106-7 (2013), p.2284 2290. 